\title{
Enhancement Mathematical Model of BLAC Motor Drive Using Rotation Coordinate for Better Output Performance
}

\author{
${ }^{1}$ Ahmed Tbrahim Jaber Alzubaydy, ${ }^{2}$ Raid A. Gaib, ${ }^{1}$ Raghad A. Mejeed and ${ }^{3}$ Alaa A. Hajer \\ ${ }^{1,3}$ Department of Power and Electrical Machine, University of Diyala, Baqubah, Iraq \\ ${ }^{2}$ Department of Electrical Engineering, University of Tromso (UiT), Tromso, Norway \\ ${ }^{3}$ Department of Power and Electrical Machine, Blad Alrafdyn University, Baghdad, Iraq
}

\begin{abstract}
In this study, design and rewrite mathematical internal of one motor simulated with nine motor with same internal circuit with different input voltage and load. The internal circuit of motor show the effect of load of the rotation speed torque at starting motor with high moment of inertia. The output of performance of simulation proves the mechanical characteristic. The new mathematical model of BLAC nine motors is design and simulated code generated by using MATLAB. The new mathematical analysis of "Internal circuit of motors" represent by mathematical equations. The specific characteristics of motor depend on mathematical analysis equations. The effect of voltage and loadon speed rotation of motor mechanical and regulation characteristic show high accuracy results where the results of simulation values confirm the motor has highly efficient in terms of possessing high mechanical properties, high range (torque, speed) in this model can use in several techniques such as Direct Torque Control (DTC) and Field Oriented Control (FOC).
\end{abstract}

$\underline{\text { Key words: BLAC, synchronous motor, simulation motor, drive, torque, BLAC, PMSM, rotor position sensor }}$

\section{INTRODUCTION}

The brushless AC motor BLAC have other name is "Permanent Magnet Synchronous Motor" drives (PMSM) with stator winding sinusoidal wave form which include Permanent Magnet Synchronous Motor (PMSM), other type of The brushless AC motor is "BLDC motor". The BLDC has feeding source current or (voltage(with stator winding trapezoidal wave form. Brushless AC motor (BLAC) is similar to induction motor drives in many applications (Zamani et al., 2013).

The PMSM or BLAC motor is comparable synchronous machine wound rotor, however, BLAC motor don't have damper windings in rotor and excitation (current or voltage) the magnetic field "Permanent magnet" in rotor its constant field due to Ferromagnetic material in rotor.

The applications of BLAC motor are famous used in different level power (low, medium) such as medical device machine (small robots), electric vehicles. Due to the problems associated with synchronous motors, BLAC motor redesign by replacing its $\mathrm{AC}$ power supply, (Tahami et al., 2011) field coil and slip rings with a Permanent Magnet (PM). The BLAC motor is a rotating electric machine with stator simplify as classic 3-phase induction motor with permanent magnets motor. In this case, BLAC motor is similar to induction motor expects rotor magnet field in BLAC motor is produced by permanent magnets. This permanent magnet use to generate a substantial air gap during magnetic flux makes it possible to design high efficient PM motors. PMSM are widely used in power applications such as computer peripheral equipment, robotics, adjustable speed drives and electric vehicles. BLAC motor is increasing in electrical and electronic device market due to smaller size, less weight, low rotor loss compare to induction motor which has same capacity. The motor drive consists of four parts as shown in Fig. 1 (Sun et al., 2012).

\section{MATERIALS AND METHODS}

The electromagnetic elements and electromechanical processes in the BLAC motor drive can calculate it in Eq. 1-5 (Sun et al., 2012):

$$
\begin{gathered}
U_{d}=R\left(T_{d} s+1\right) i_{d}-\omega L_{q} i_{q} \\
U_{q}=R\left(T_{q} s+1\right) i_{q}-\omega L_{d} i_{d}+\varphi_{0} \omega \\
M=p \frac{m}{2}\left(\Psi_{0} i_{q}+\left(L_{d}-L_{q}\right) i_{d} i_{q}\right) \\
s \omega_{m}=\frac{1}{J}\left(M-M_{H}\right)
\end{gathered}
$$

Corresponding Author: Ahmed Ibrahim Jaber Alzubaydy, Department of Power and Electrical Machine, University of Diyala, Baqubah, Iraq 


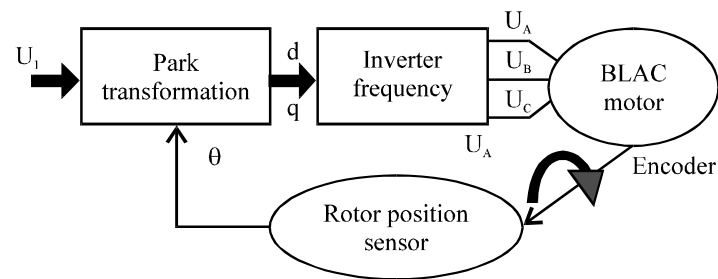

Fig. 1: BLAC motor system diagram system

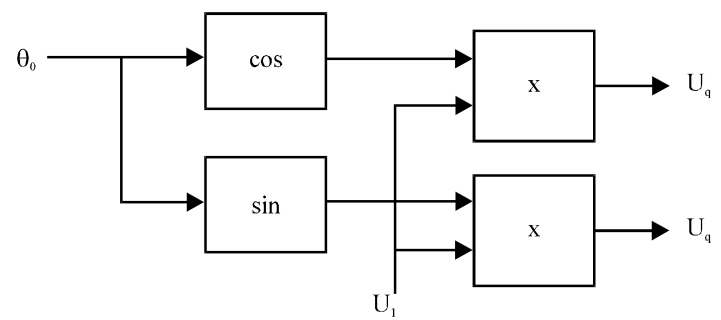

Fig. 2: Transformation coordinate to $d_{q}$ axis

$$
\mathrm{s} \theta_{\mathrm{m}}=\omega_{\mathrm{m}}, \omega=\mathrm{p} \omega_{\mathrm{m}}
$$

The voltages $U_{d}, U_{q}$ could be set independently of each other and their values could linked to the initial value setting of the rotor position sensor, in this case, the voltage will determined and calculate in Eq. 6 and 7 (Tahami et al., 2011):

$$
\begin{aligned}
& \mathrm{U}_{\mathrm{d}}=\mathrm{U}_{1} \mathrm{~K}_{\mathrm{cp}} \cos \theta_{0}=\mathrm{U}_{1} \cos \theta_{0} \\
& \mathrm{U}_{\mathrm{q}}=\mathrm{U}_{1} \mathrm{~K}_{\mathrm{cp}} \sin \theta_{0}=\mathrm{U}_{1} \sin \theta_{0}
\end{aligned}
$$

The voltage transformation coordinate $(\mathrm{d}, \mathrm{q})$ axis with rotor position sensor will be as rotor position. Angle $\left(\theta_{0}\right)$ as in Fig. 2. The three phase current $\mathrm{ABC}$ convert to two axes rotation frame as in Eq. 8-11 (Hussein and Jaber, 2017):

$$
\begin{gathered}
\left(\begin{array}{l}
i_{\mathrm{a}} \\
i_{\mathrm{b}} \\
i_{\mathrm{c}}
\end{array}\right)=\sqrt{\frac{2}{3}}\left[\begin{array}{cc}
\cos \left(\theta_{\mathrm{e}}\right) & -\sin \left(\theta_{\mathrm{e}}\right) \\
\cos \left(\theta_{\mathrm{e}}+\frac{4 \pi}{3}\right) & -\sin \left(\theta_{\mathrm{e}}+\frac{4 \pi}{3}\right) \\
\cos \left(\theta_{\mathrm{e}}+\frac{2 \pi}{3}\right) & \cos \left(\theta_{\mathrm{e}}+\frac{2 \pi}{3}\right)
\end{array}\right]\left(\begin{array}{l}
\mathrm{i}_{\mathrm{d}} \\
\mathrm{i}_{\mathrm{q}}
\end{array}\right) \\
\mathrm{i}_{\mathrm{a}}=\left(\sqrt{\frac{2}{3}} \cos \left(\theta_{\mathrm{e}}\right) \mathrm{i}_{\mathrm{d}}-\sqrt{\frac{2}{3}} \sin \left(\theta_{\mathrm{e}}\right) \mathrm{i}_{\mathrm{q}}\right) \\
\mathrm{i}_{\mathrm{b}}=\left(\sqrt{\frac{2}{3}} \cos \left(\theta_{\mathrm{e}}+4.18879\right) \mathrm{i}_{\mathrm{d}}-\sqrt{\frac{2}{3}} \sin \left(\theta_{\mathrm{e}}+4.18879\right) \mathrm{i}_{\mathrm{q}}\right)
\end{gathered}
$$

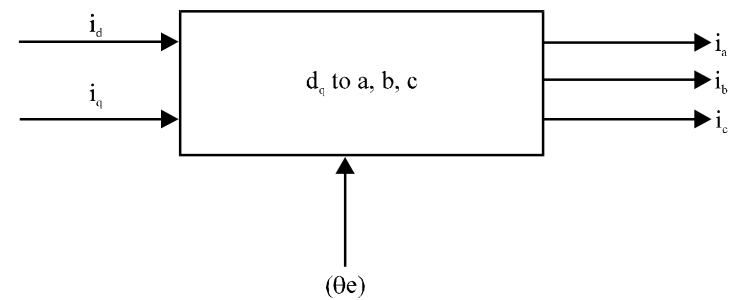

Fig. 3: $i_{d}-i_{q}$ to $i_{a}, i_{b}, i_{c}$ transformation block

$$
\mathrm{i}_{\mathrm{c}}=\left(\sqrt{\frac{2}{3}} \cos \left(\theta_{\mathrm{e}}+2.094395\right) \mathrm{i}_{\mathrm{d}}-\sqrt{\frac{2}{3}} \sin \left(\theta_{\mathrm{e}}+2.094395\right) \mathrm{i}_{\mathrm{q}}\right)
$$

where, the main parameter in Eq. 1-11 are:

- BLAC: Brushless AC motor

- $\mathrm{U}_{\mathrm{d}}, \mathrm{U}_{\mathrm{q}}, \mathrm{i}_{\mathrm{d}}, \mathrm{i}_{\mathrm{q}}$ : projections of the stator voltage and current $(\mathrm{d}, \mathrm{q})$

- $\mathrm{W}_{\mathrm{m}}$ : mechanical angular speed

- $\theta_{\mathrm{m}}$ : mechanical angle of rotation of the shaft

- M: electromagnetic torque

- $\mathrm{K}_{\mathrm{cp}}$ : coefficient of power semiconductor converter

Figure 3 showing design system of transformation coordinate $\mathrm{d}-\mathrm{q}$ to $\mathrm{ABC}$ by Simulink depending on equations from Eq. 8-11 as in Fig. 4 (Hussein and Jaber, 2017).

In order to simplify of a mathematical description of $\mathrm{BLAC}$ motor drive, the operation equation that describes electromagnetic processes in BLAC motor can be written as new develop (Eq. 12-16):

$$
\begin{gathered}
U_{d}+\omega L_{q} i_{q}=L_{d} \frac{d i_{d}}{d t}+R i_{d} \\
U_{d}=R\left(T_{d} s+1\right) i_{d}-\omega L_{q} i_{q} \\
U_{q}-\omega L_{q} i_{q}-\varphi_{0} \omega=L_{q} \frac{d i_{q}}{d t}+R i_{q} \\
M=p \frac{m}{2}\left(\Psi_{0} i_{q}+\left(L_{d}-L_{q}\right) i_{d} i_{q}\right) \\
\frac{d \omega_{m}}{d t}=\frac{1}{J}\left(M-M_{H}\right)
\end{gathered}
$$

where, parameter from Eq. 12-16 shows that: $\mathrm{M}_{\mathrm{H}}$ : load torque $\mathrm{T}_{\mathrm{d}}$ : the Time (sec) in coordinate axis (direct) $\mathrm{T}_{\mathrm{q}}$ : the Time ( $\mathrm{sec}$ ) in quadrature axis 


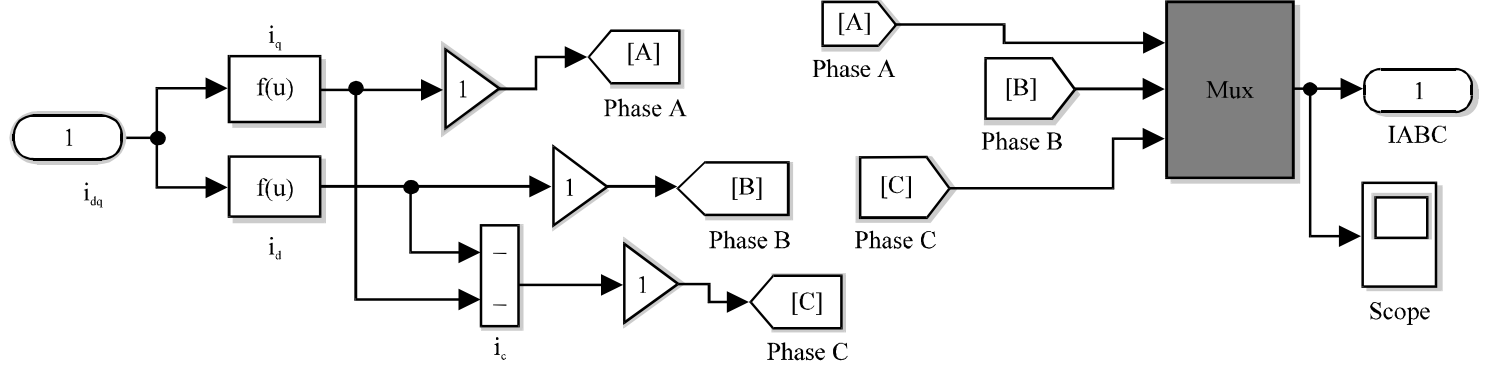

Fig. 4: d-q to $A B C$ transformation Simulink block

$\mathrm{J}$ : moment of inertia of the rotor

$\mathrm{L}_{\mathrm{d}}, \mathrm{L}_{\mathrm{q}}$ : internal circuit inductance $\mathrm{mH}$ two axis $\mathrm{d}, \mathrm{q}$

FOC: Field Oriented Control

DTC: Direct Torque Control

DTC: variable frequency drive

\section{RESULTS AND DISCUSSION}

Simulation and results: Mathematical model is implemented simulated from the new rewriting the original Eq. 1-5 BLAC motor to gate develop new mathematical equation shown in Eq. 12-16 (Fig. 5). Since, this internal circuit diagram of BLAC show the characteristic (speed, torque, coordination current $\mathrm{q}, \mathrm{d}$ and stator current $\mathrm{ABC}$ by rotating coordinate frame. Using Table 1 represent the real parameters of the BLAC motor that used to test the new mathematical model Fig. 5 of the BLAC motor.

New design of BLAC motors system consist 9 motors at no-load, load $(5,10 \mathrm{Nm})$ with different voltages and colors Fig. 6, each color related to different operations depend on different input voltages and load. The block system of nine motors has same internal circuit Fig. 5 with different output characteristics. First motors system with yellow color running at no load, since, motors with cyan color running in $5 \mathrm{Nm}$, motors with gray $10 \mathrm{Nm}$ all block system it has different input voltages $\left(\mathrm{U}_{\mathrm{q}}\right)$ volt.

The 9 motors starting with high transit current response which it reflect on balancing system until steady state $0.05 \mathrm{sec}$ from simulation of no load, $5,10 \mathrm{Nm}$. Figure 7-9 behaver same with different peak value. The first group of motors yellow color at no load have $\mathrm{ABC}$ steady state output current at $4 \mathrm{~A}$ shown in Fig. 7, since, the steady state current $\mathrm{ABC}$ will be $6 \mathrm{~A}, 8 \mathrm{~A}, 5,10 \mathrm{Nm}$, respectively because of the load effect at time $0.3 \mathrm{sec}$.

The output currents of rotating coordinate frame $d_{q}$, Fig. 10-12 shows the increase current at $0.3 \mathrm{sec}$ with different load 0.5 and $10 \mathrm{Nm}$ the increase of the shape of current because of load effect.

The new mathematical model of block system has speed and torque. The block system have different running speed. The output of Fig. 13-15 will operate at 5,

\begin{tabular}{lll}
\multicolumn{2}{l}{ Table 1: Real parameters of the BLAC motor } \\
\hline Parameters & Values & Units \\
\hline $\mathrm{R}$ & 0.96 & $\Omega$ \\
$\mathrm{L}_{\mathrm{d}}, \mathrm{L}_{\mathrm{q}}$ & 0.03 & $\mathrm{H}$ \\
$\theta_{0}$ & 0.183 & weber \\
$\mathrm{J}$ & 0.0013 & $\mathrm{Kgm}^{2}$ \\
$\mathrm{P}$ & 8 & - \\
\hline
\end{tabular}

Table 2: Mechanical characteristic of BLAC motor drive

\begin{tabular}{llrc}
\hline & \multicolumn{1}{l}{$\omega_{\mathrm{m}}$} & & \\
Load torque & $\mathrm{U}_{\mathrm{q}}=10$ & $\mathrm{U}_{\mathrm{q}}=20$ & $\mathrm{U}_{\mathrm{q}}=30$ \\
\hline 0.00 & 13.66 & 27.32 & 40.98 \\
5.00 & 7.64 & 20.9 & 33.77 \\
10.00 & 1.719 & 15.06 & 27.65 \\
15.00 & -4.533 & 9.4 & 22.09 \\
20.00 & -11.82 & 3.57 & 16.77 \\
\hline
\end{tabular}

20 and $45 \mathrm{~V}$, respectively. The output speed of system at no-load condition will rotate at 6,27 and 65 rps. That mean by increase the input voltage $U_{q}$ will increase the rotation speed. With $5,10 \mathrm{Nm}$ at time $0.3 \mathrm{sec}$ the rotation speed will decrease 8 and $10 \%$ at Fig. 14 and 15 .

To illustrate the relation of rotor speed for several values of voltages under changing load for three levels, the relationship between them prove by increase $\mathrm{U}_{\mathrm{q}}$ input voltage will increase rotation speed Fig. 16 . The relationship between voltage and speed with stator current $U_{\mathrm{q}}$ proved by increasing supply voltage at 0.3 $\mathrm{sec}$ it causes increase the speed of motor as Fig. 17 and 18. Table 2 mechanical characteristic of system prove the effect of load torque variation on rotation speed for three value of $\mathrm{U}_{\mathrm{q}} 10,20,30 \mathrm{~V}$ will prove mechanical characteristics of BLAC motor as in Fig. 19.

The relationship between voltage and speed with stator current $\mathrm{U}_{\mathrm{q}}$ proved by increasing supply voltage at $0.3 \mathrm{sec}$ it causes increase the speed of motor as Fig. 17 and 18 . Table 2 mechanical characteristic of system prove the effect of load torque variation on rotation speed for three value of $U_{q} 10,20,30 \mathrm{~V}$ will prove mechanical characteristics of BLAC motor as in Fig. 19.

To prove our enhancement of the design machine by taking one internal machine linked to workshop suitable 


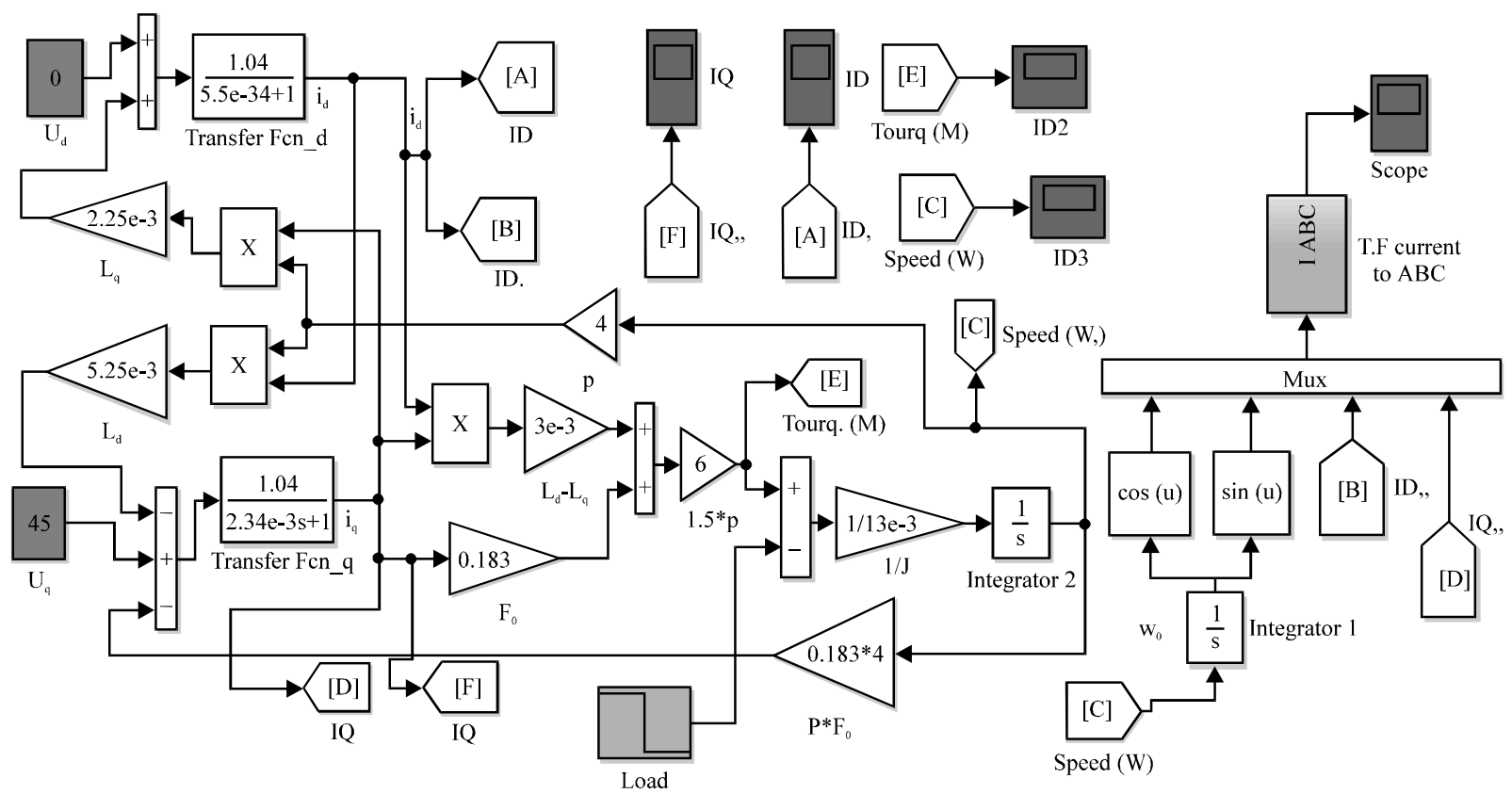

Fig. 5: Mathematical model of internal system BLAC motor drive in a rotating coordinate system

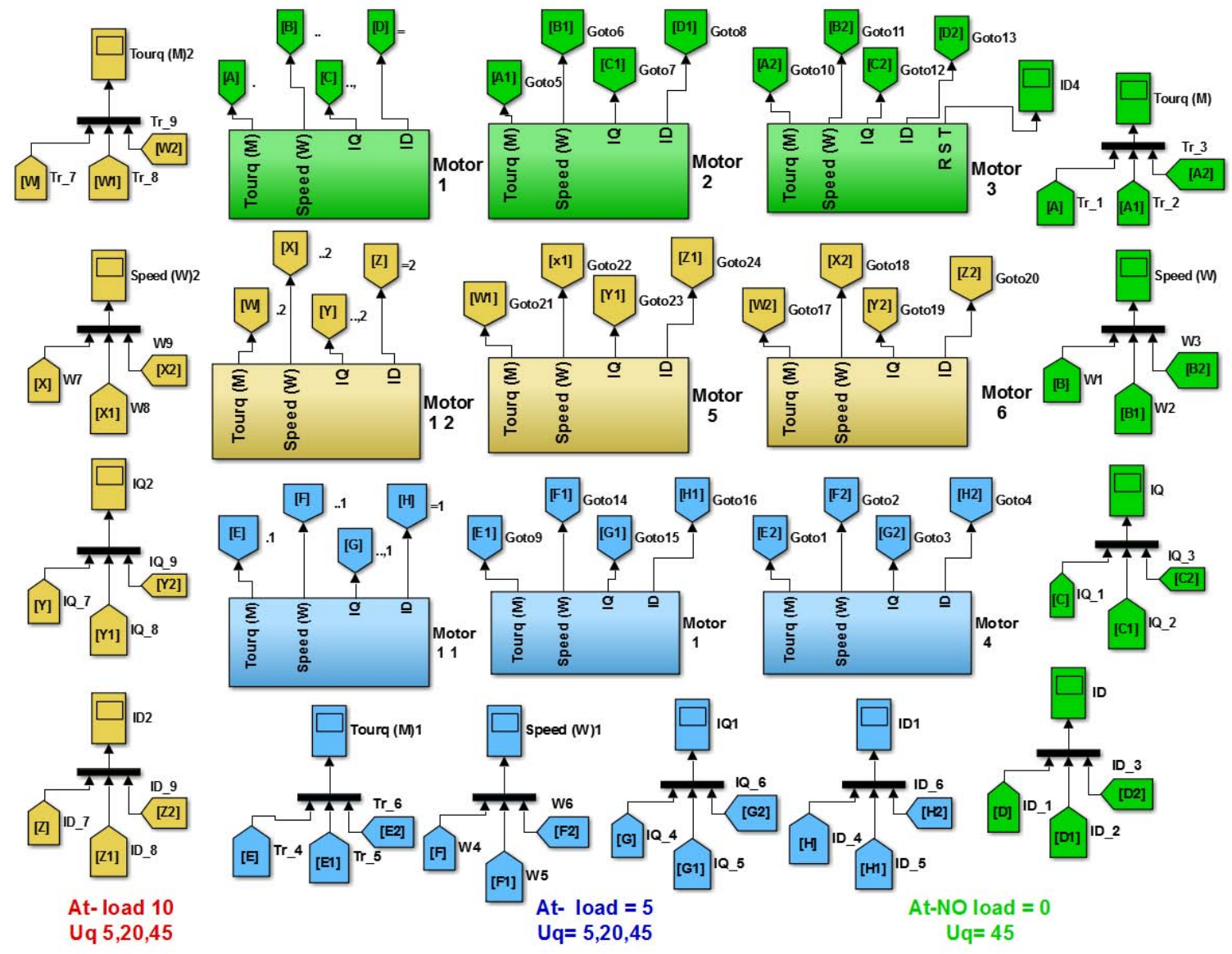

Fig. 6: Three block motors system BLAC at no load with different voltages 


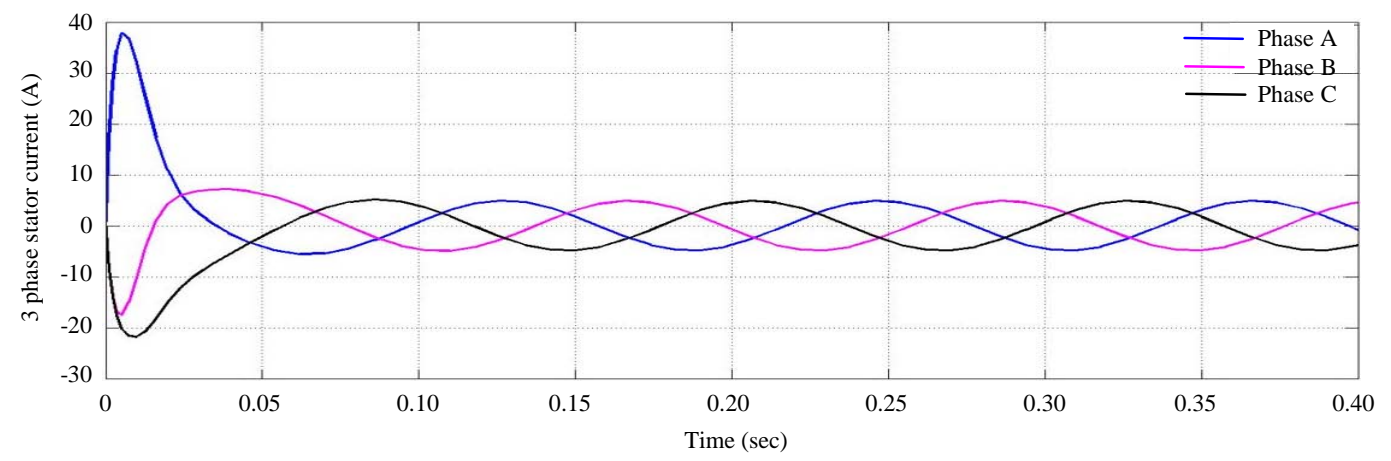

Fig. 7: Three phase stator current at no load

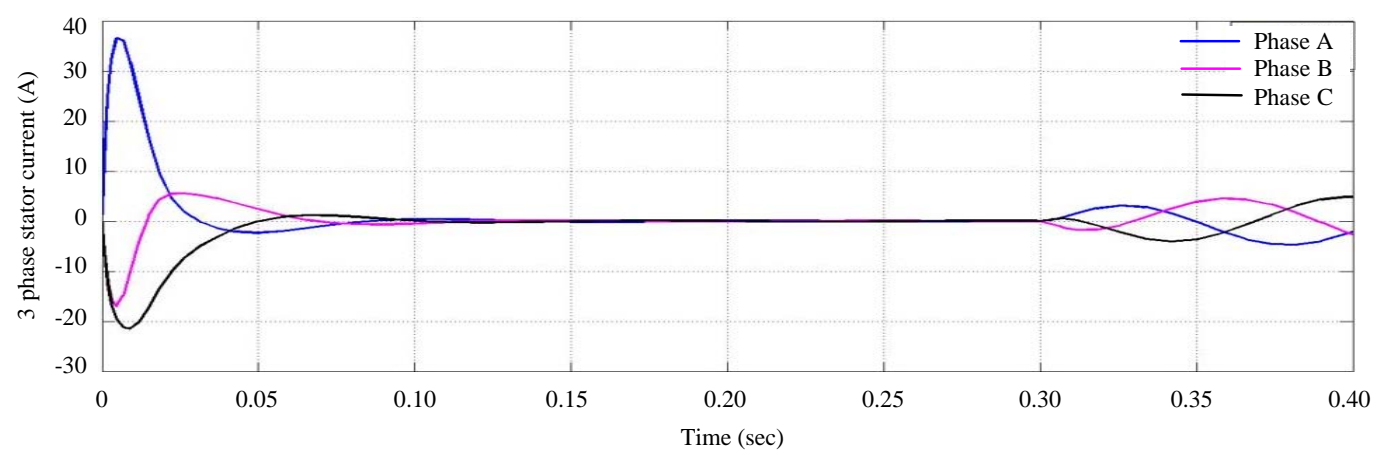

Fig. 8: Three phase stator current at $5 \mathrm{Nm}$ load

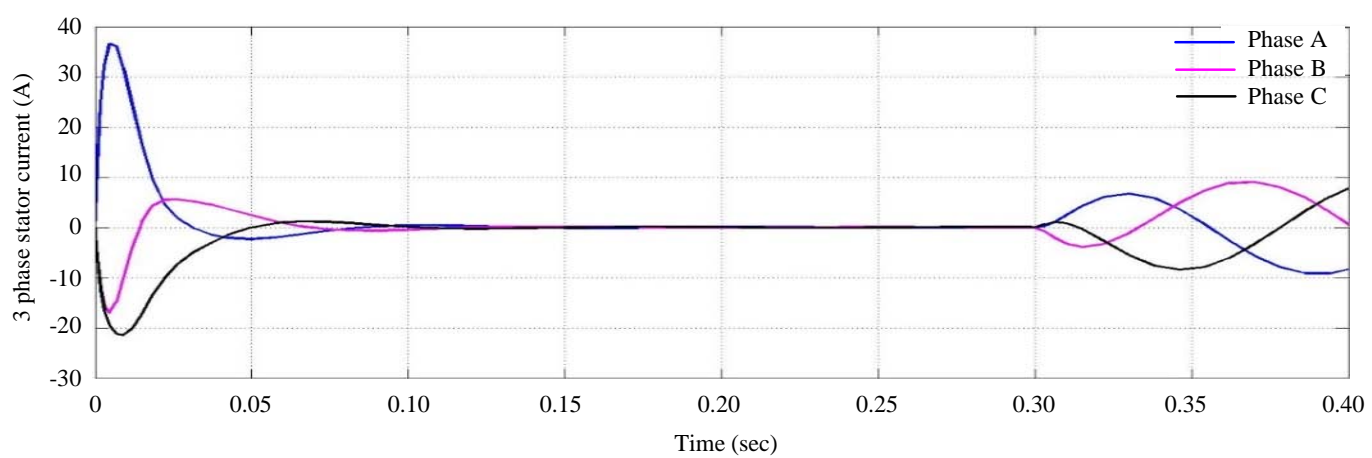

Fig. 9: Three phase stator current at $10 \mathrm{Nm}$ load

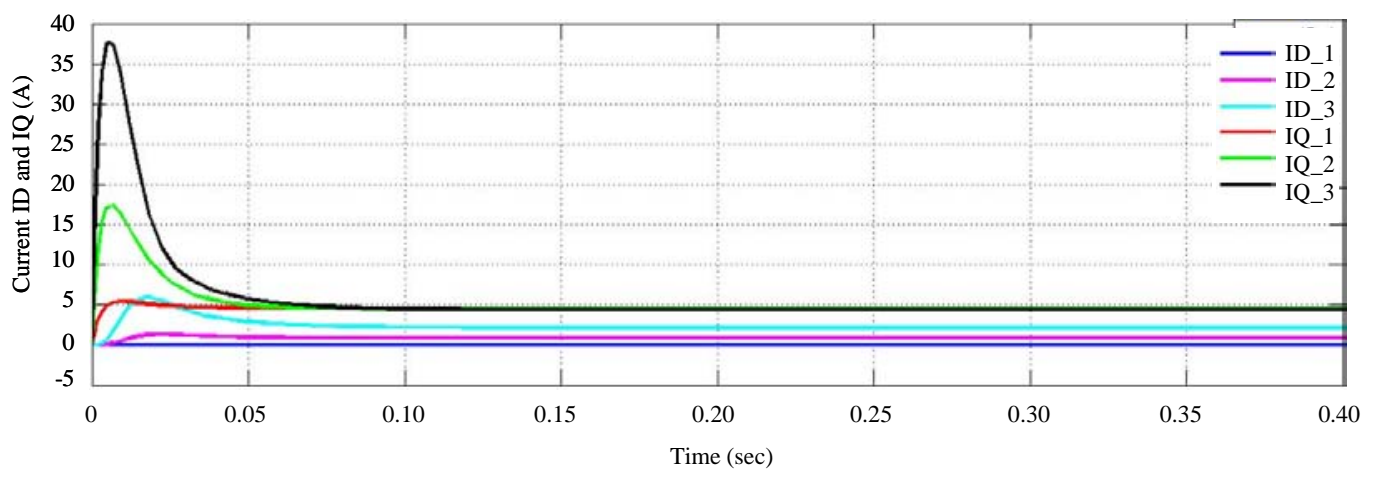

Fig. 10: Coordinate system current $\mathrm{d}-\mathrm{q}$ axis at varying voltage at no load 


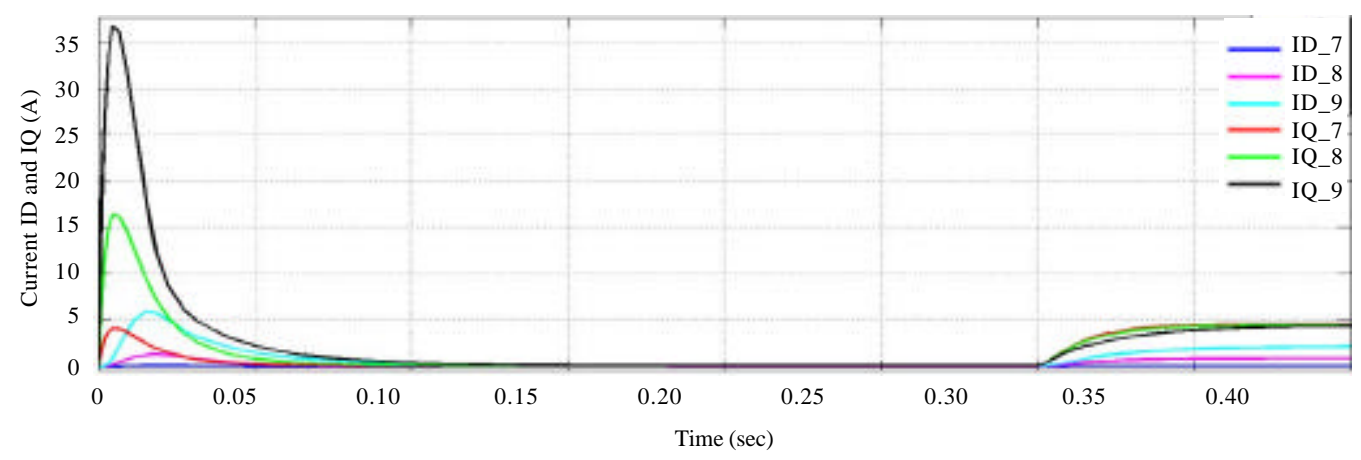

Fig. 11: Coordinate system current $d-q$ axis at varying voltage at load $5 \mathrm{Nm}$

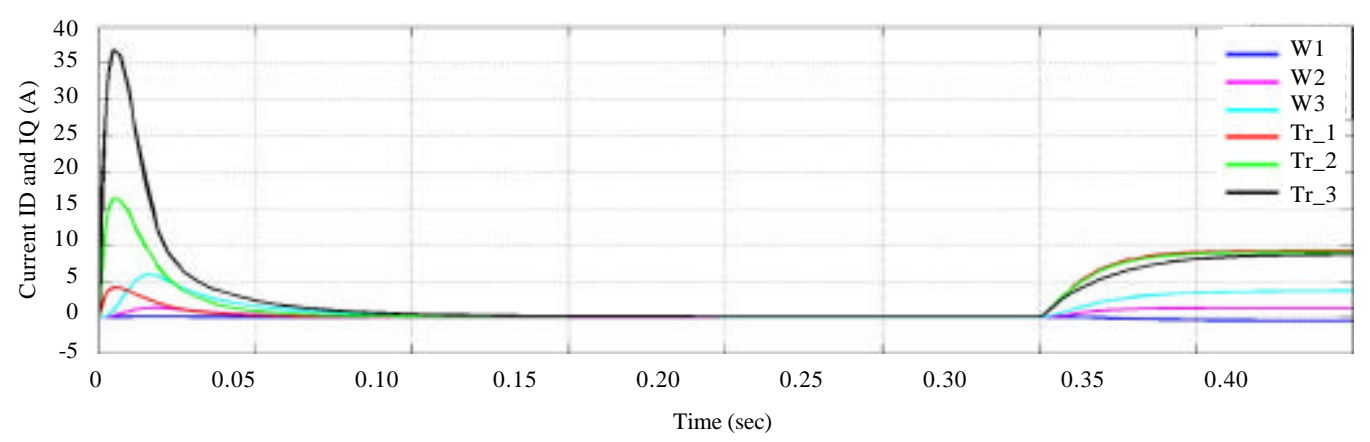

Fig. 12: Coordinate system current $\mathrm{d}-\mathrm{q}$ axis at varying voltage at $10 \mathrm{Nm}$ load

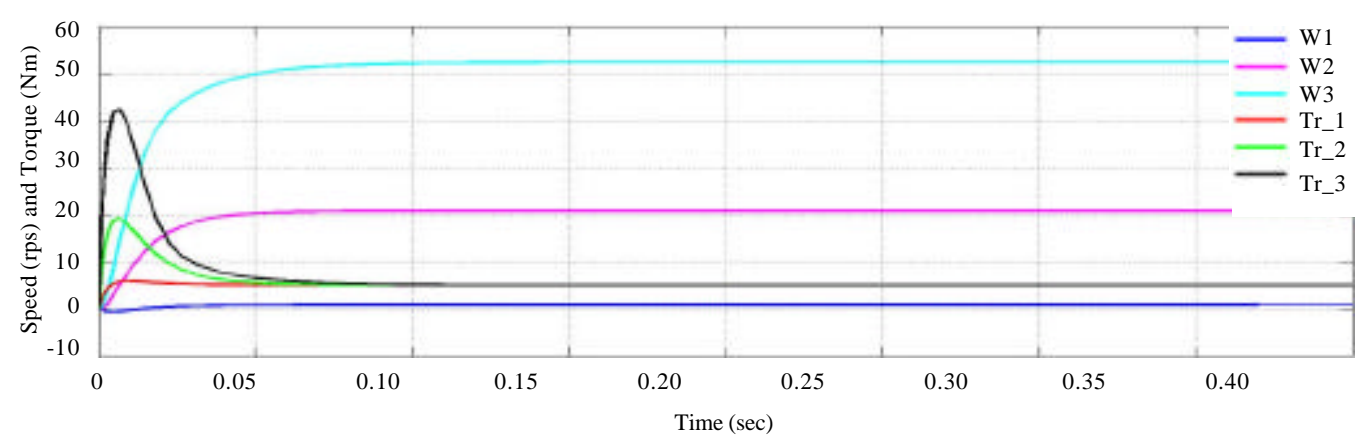

Fig. 13: Rotor speed (rps) and electromagnetic torque $(\mathrm{Nm})$ at no-load with different voltage

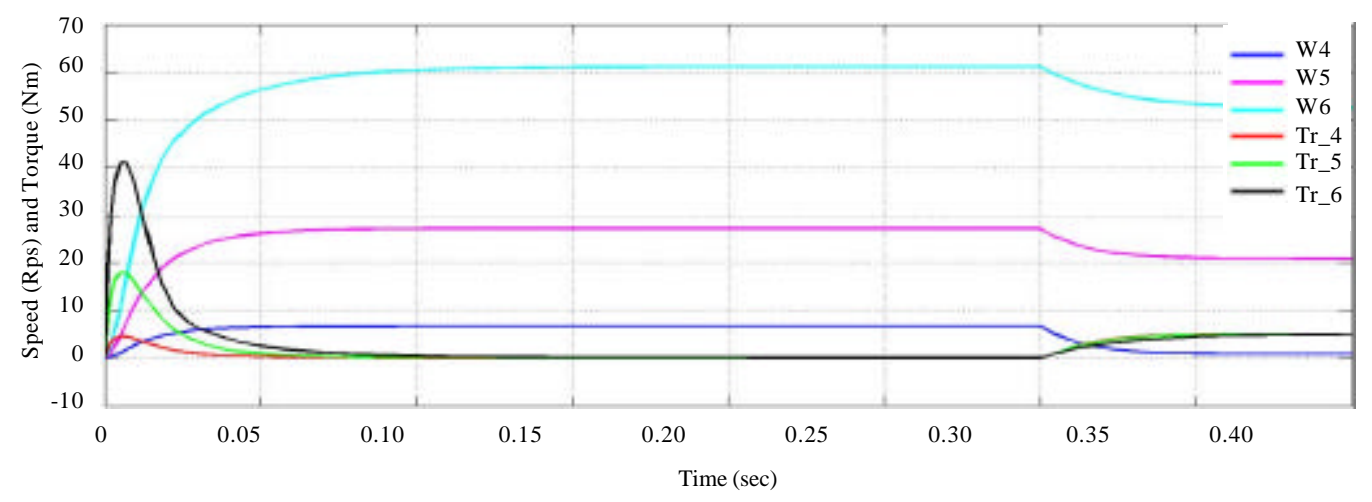

Fig. 14: Rotor speed and electromagnetic torque at $(5 \mathrm{Nm})$ Load 


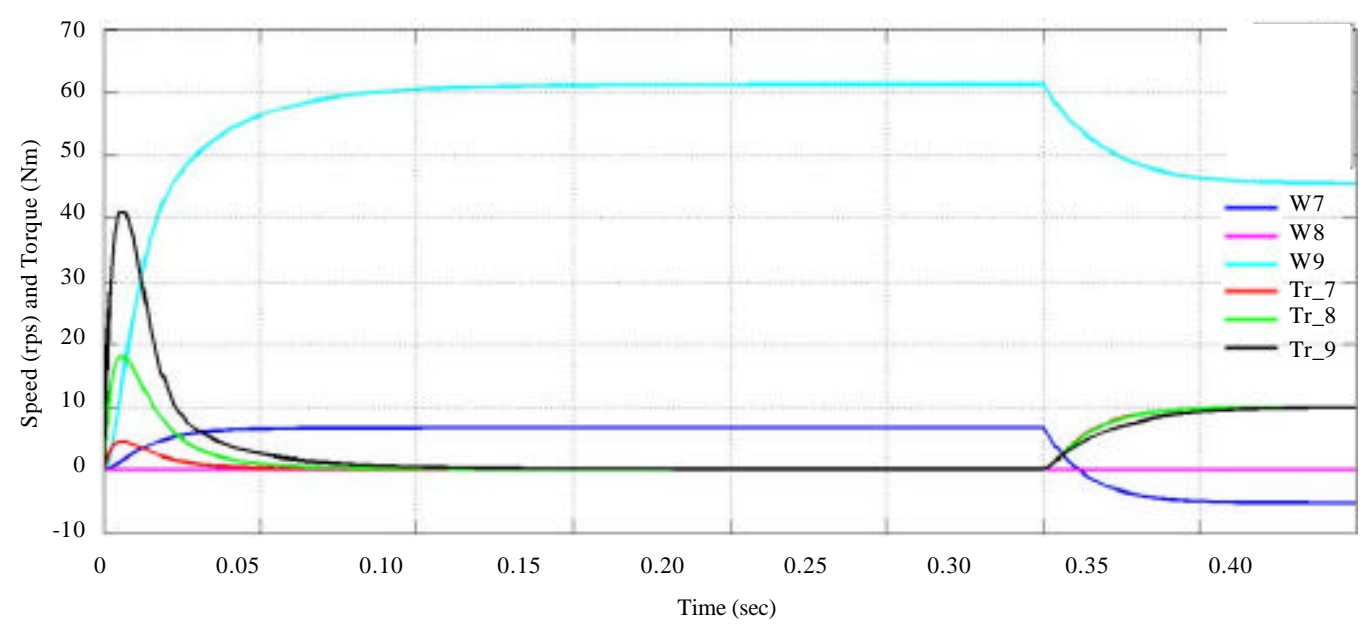

Fig. 15: Rotor speed and electromagnetic torque at $10 \mathrm{Nm}$ load

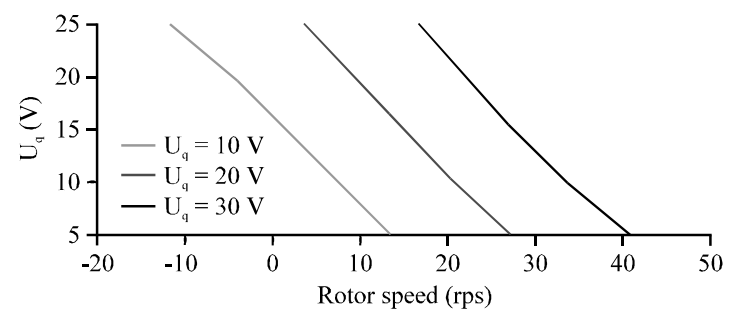

Fig. 16: Relation between $U_{q}$ and rotor speed

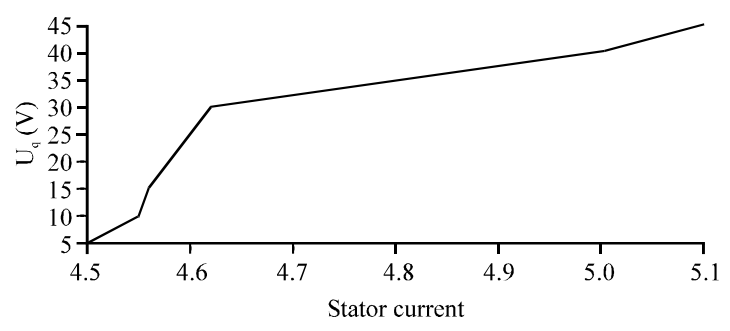

Fig. 17: Relation between rotor speed (rps) and stator current (A)

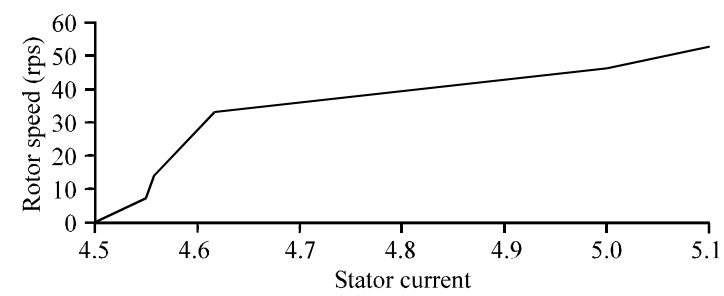

Fig. 18: Relation between $\mathrm{U}_{\mathrm{q}}(\mathrm{V})$ and stator current $(\mathrm{A})$

MATLAB code taking in account all variable scope. The porameters are calculated and exporeted to the $\mathrm{M}$ file result. This result which get it from the work shop used to assist our approach showning in Fig. 20 and 21.

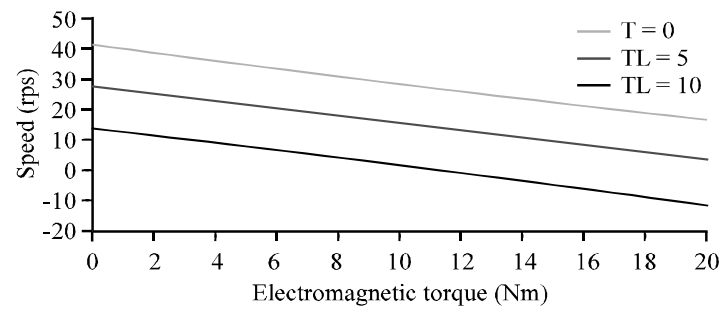

Fig. 19: Prove the mechanical characteristic for PMSM

The quality of static charachteristic consider as function rotantional speed and toque, since, the instante voltage is $=400 \mathrm{~V}$. In other side the electromagnetic field occurdinly depended on internal current supply and consuming motor current. The realtion of total power, active power and pdc with $\mathrm{M}$ file work shop shown briefly by the German-Galkin (2010). The electrical energy charactarestics depends on active power and input powerin following figures the correspond of the power PDC invertare and the input power thats mean the efficiency of the machine are optimized. Also the relation between input current, IDC inverter with development speed locking different trajectory but the both have the same design value.

Related totopology the compartment between this study and other suggested articles topics show the main interest in there topics have other interestlike "Those reference (Tahami et al., 2011; Zodape, 2015; Venna et al., 2013; Singh, 2012)" included many aspect with different trend result by choosing the dynamic equations to analys the result as by Tahami et al. (2011), Zodape (2015); Venna et al. (2013) and Singh (2012). But I have chose uniqe analyzing destination by taking the rewrite dyanamic equations and proving the relationship between 


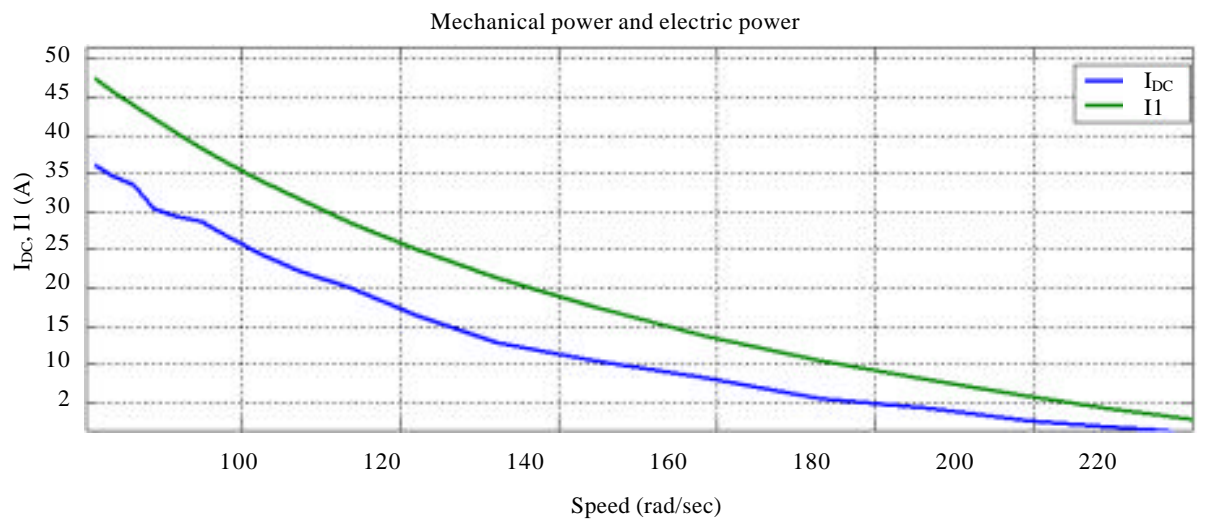

Fig. 20: The relation between input current (A), DC current (A) supplies with rotation speed (rps)

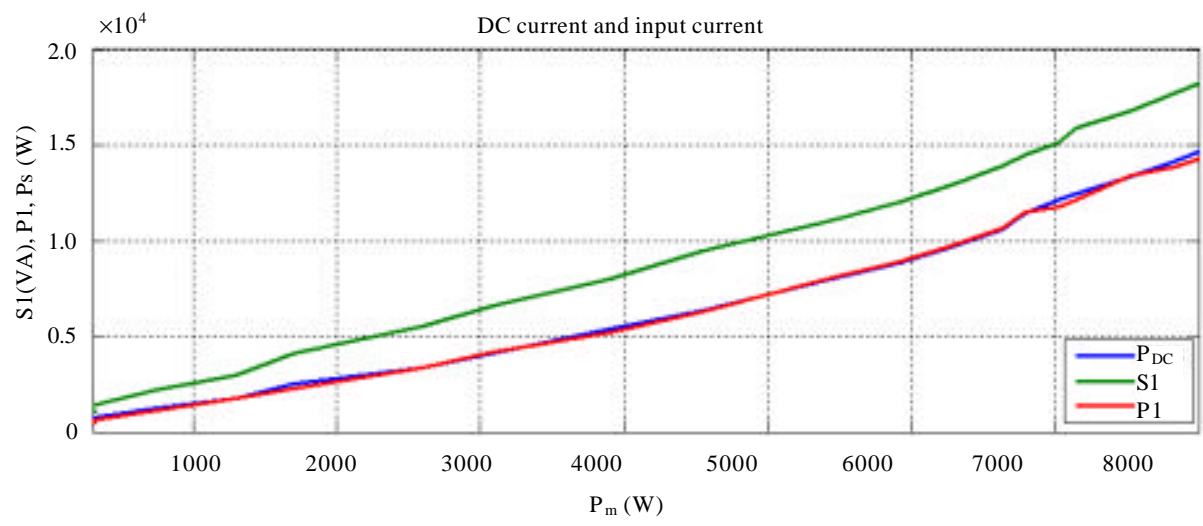

Fig. 21: Realtion beteween PDC (W), input power (W), active power (VA) with shift power (W)

voltage, rotor speed with stator current and regulator characteristic. Finally simulation and result showing behavior of internal circuit from efficiency of one motor of BLAC motor drive has high characteristics and efficiency.

\section{CONCLUSION}

This study present mathematical analysis, modeling and simulation of rotor position sensor BLAC nine motors at no-load, load $(5,10 \mathrm{Nm})$ with different voltage. The design for each 3 motors have different color related to different operations depend on input voltages and load. The block system of nine motors has same internal circuit. First motors system running at no load, other motors running at $5,10 \mathrm{Nm}$, respectively, all block system it has different input voltages. The BLAC motor drive under different operating condition load and voltage. The result of model shows that system motors drive behavior high acceleration and it can run smoothly with good static as well as dynamic performance. It mean it run more efficient applications. The result of design improve specific of each motor BLAC speed torque and stator current. This improves how the regulator characteristics and mechanical characteristics of nine motors have same internal circuit. The motors work under different condition voltage and torque up to any voltage. In this study, BLAC motor has stiff mechanical characteristics has wide range of speed control with has high value of overload torque and efficiency more than $97 \%$. This characteristics attempt to added enhance of output machine show "Realtion between PDC (W), input power with shift power". The conclucion represented one machine of system related the relations between (speed, voltage supply and regulator charactaristics, when the load or supply voltage varying with stator current. Finally concluded that modeling BLAC system drive implemented by MATLAB Simulink and code) running of different operating conditions. This model could use several techniques such as VFD method, Direct Torque Control (DTC) method and Field Oriented Control (FOC).

\section{ACKNOWLEDGEMENTS}

I sincerely acknowledge the support of received from Dr. M.S. Hasan and my family and all those whose helped me at Dayala University during may writing possesses. 


\section{REFERENCES}

German-Galkin, S., 2010. Computer simulation of semiconductor systems MATLAB 6.0. Korona Print, Saint Petersburg, Russia, ISBN:13-9785793108133 ,

Hussein, H.I and A.I. Jaber, 2017. Openloop and close loop vector control of VFD three phase version induction motor drives. Diala J. Eng. Sci., 10: 27-38.

Singh, B., 2012. Performance evaluation of direct torque control with permanent magnet synchronous motor. Bull. Electr. Eng. Inf., 1: 165-178.

Sun, T., C. Liu, N. Lu, D. Gao and S. Xu, 2012. Design of PMSM vector control system based on TMS320F2812 DSP. Proceedings of the 2012 7th International Conference on Power Electronics and Motion Control (IPEMC) Vol. 4, June 2-5, 2012, IEEE, Harbin, China, ISBN:978-1-4577-2085-7, pp: 2602-2606.
Tahami, F., H. Nademi and M. Rezaei, 2011. Maximum torque per ampere control of permanent magnet synchronous motor using genetic algorithm. TELKOMNIKA Telecommun. Comput. Electron. Control, 9: 237-244.

Venna, S.G.R., S. Vattikonda and S. Mandarapu, 2013. Mathematical modeling and simulation of permanent magnet synchronous motor. Intl. J. Adv. Res. Electr. Electron. Instrum. Eng., 2: 3720-3726.

Zamani, H., M.H. Karimi, K. Kanzi and Q. Vasheghani, 2013. Vector control of counter-rotating permanent magnet synchronous motor for underwater propulsion application. Proceedings of the 2013 4th International Conference on Power Electronics, Drive Systems and Technologies (PEDSTC), February 13-14, 2013, IEEE, Tehran, Iran, ISBN:978-1-4673-4481-4, pp: 44-48.

Zodape, P., 2015. Direct torque control of permanent magnet synchronous motor. Intl. J. Novel Res. Electr. Mech. Eng., 2: 25-36. 